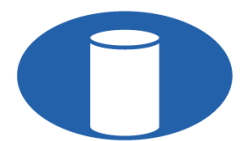

IBRACON Structures and Materials Journal

Revista IBRACON de Estruturas e Materiais

IBRACON

ISSN 1983-4195 ismj.org

ORIGINAL ARTICLE

\title{
Numerical and experimental comparative of coupled neighboring buildings
}

\section{Comparativo numérico e experimental de edificações vizinhas acopladas}

\author{
Luis Alejandro Perez Peña ${ }^{a}$ \\ Graciela Nora Doz ${ }^{\mathrm{b}}$ (i) \\ Suzana Moreira Avilac
}

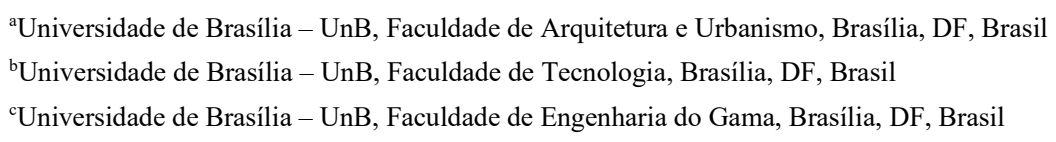

Received 07 August 2019

Accepted 28 April 2020

\begin{abstract}
In recent years a vibration control technique, called structural coupling, has been studied. This technique consists on linking two neighboring buildings, through a coupling device, with the purpose of reducing dynamic response. It is possible to control both structures response simultaneously, which is precisely the attractiveness of this technique. Given the potential of the structural coupling technique, this work evaluates numerically and experimentally the performance of the structural coupling technique in simple plane frames when subjected to an oscillatory movement in at base caused by a shaking table, designed and built in the Structure Laboratory of University of Brasilia. Initially, the model numerical dynamic responses, without and with coupling, were obtained. Then, experimentally, the plane frames were fixed to the shaking table and subjected to a base movement uncoupled and coupled in order to obtain the acceleration registers and its frequency spectra. Finally, numerical and experimental frequency spectra were compared. The results obtained showed the efficiency of the control method through coupling, which depends mainly on the mechanical properties of adjacent buildings and connecting devices.
\end{abstract}

Keywords: seismic analysis, structural dynamics, structural control, coupled building.

Resumo: Nos últimos anos têm sido implementada uma técnica de controle de vibrações chamada de acoplamento estrutural. Essa técnica consiste em ligar duas edificações vizinhas por meio de um dispositivo de acoplamento, com o objetivo de diminuir os efeitos dinâmicos em função das propriedades mecânicas de cada estrutura. Ao fazê-lo, em princípio, é possível controlar a resposta de ambas as estruturas simultaneamente, o que é precisamente a atratividade da técnica. Dado o seu potencial, este trabalho tem como objetivo avaliar numérica e experimentalmente a eficácia dela utilizando pórticos planos simples quando submetidos a um movimento oscilatório na base provocado por uma mesa vibratória, projetada e construída no Laboratório de Estruturas da Universidade de Brasília. Inicialmente, foram calculadas as respostas dinâmicas numéricas dos modelos com e sem acoplamento. Em seguida, experimentalmente, os pórticos planos foram fixados na mesa vibratória e foram submetidos a um movimento na base quando desacoplados e acoplados a fim de obter os registros de acelerações e assim obter seus espectros de frequência. Finalmente, foram comparados os espectros obtidos experimentalmente com os obtidos numericamente. Os resultados apresentados mostraram a eficiência do método de controle por meio do acoplamento, a qual foi afetada principalmente pelas propriedades mecânicas dos edifícios adjacentes e dos elementos de conexão.

Palavras-chave: análise sísmica, dinâmica estrutural, controle estrutural, acoplamento estrutural.

How to cite: L. A. Perez Peña, G. N. Doz, and S. M. Avila, "Numerical and experimental comparative of coupled neighboring buildings," Rev. IBRACON Estrut. Mater., vol. 13, no. 6, e13609, 2020, https://doi.org/10.1590/S1983-41952020000600009

Corresponding author: Luis Alejandro Perez Peña. E-mail: alejandrop@unb.br

Financial support: CNPq Brazilian Council of National Scientific and Technological Development and Federal District Research Support Foundation (FAPDF). Conflict of interest: Nothing to declare. 


\section{INTRODUCTION}

With the cities development there is a tendency of population increase in large urban centers, causing thus a shortage of spaces and making tall buildings a characteristic of modern cities. These types of buildings because of their height and high mass concentration characteristics are very vulnerable to collapse in the presence of one of the most destructive phenomena of nature: the earthquake. These vibrations are undesirable from the point of view of both comfort and safety.

To work avoiding this problem, medium- and high-rise structures started employing control techniques such as tuned mass dampers (TMDs) to help mitigate excessive vibrations and deformations when subjected to dynamic loads. According to Watanabe et al. [1], one of the drawbacks when a single TMD is used in flexible structures is its sensitivity to any discrepancy in the natural frequency of the structure and the TMD damping. As a solution for this problem, multiple tuned mass dampers with different dynamic characteristics are used. However, the control system becomes expensive.

Thus, a control technique called structural coupling, which consists of connecting two or more neighboring buildings through coupling devices to provide reaction control forces, showed to be a viable alternative for the protection of adjacent flexible structures. This technique can be applied to a wide variety of structural systems and can incorporate various types of control strategies including passive, active, or semiactive control [2], [3].

The application of the coupling technique to civil structures has received much attention from the 90's since it was first proposed by Klein et al. [4] and Kunieda [5]. Theoretical, numerical and experimental approaches of coupled structures were performed in order to demonstrate the viability of this technique [6]-[34]. These studies showed that the efficiency of the coupling technique depends on the mechanical and geometrical properties of the neighboring buildings, as well as on the mechanical properties of the connecting device.

In addition to these analytical and experimental research, a few full-scale applications of coupled building control have been undertaken. In 2001, the Triton Square office complex, located on the Tokyo waterfront on Harumi Island, completed construction. The complex is a cluster of three buildings, 195, 175, and $155 \mathrm{~m}$ high, respectively. The three buildings are coupled with two active control actuators for wind and seismic protection [35], [36]. In 2013, between the Chiesa del Sacro Cuore (Florence - Italy) and R/C bell tower, passive viscofluid shock absorbers were installed in order to reduce the pounding between them [37].

It should be noted that most researches on the coupling technique were performed in countries located in areas with a high risk of seismicity and high economic development. In Latin American countries, research related to this technique are still incipient. Thus, this work evaluates numerically and experimentally the performance of the structural coupling technique in simple plane frames when subjected to an oscillatory base movement caused by a shaking table, designed and built in the Structure Laboratory of University of Brasilia. It should also be noted that, even using steel plane frames, the results can be extended to concrete or other materials frames.

\section{METHODOLOGY}

In a previous stage, numerical preliminary models were developed to set material type and dimensions of the plane frames to be tested. Then, the shear building frames were constructed and tested to identify dynamic properties such as frequencies, vibration modes and damping factors using the ARTeMIS Modal software [38]. It should be noted that in the shear building model a degree of freedom per floor is considered, therefore, for each of these degrees a frequency value is associated.

Subsequently, numerical models were validated using the correlation of the natural frequencies and the vibrational modes, numerical and experimental, using the percentage of variation of the frequency (FER) and the Modal Assurance Criterion (MAC) [39], [40]. This validation is important to ensure that the numerical models represented the actual physical behavior of the tested plane frames.

Once validation was done, an optimization study was performed using the particle swarm optimization (PSO) [41] in a way to set the connecting device properties. Next, the device that was used in the experimental tests was built.

Then, a numerical and experimental analysis were performed to evaluate the performance of the coupling technique in reducing the amplitudes of the dynamic responses of the adjacent shear frames. For this purpose, the acceleration records and the frequency spectra of each structure were obtained and compared. All numerical analysis, as well as the treatment of experimental data, were performed using MATLAB [42]. 


\section{MATHEMATICAL FORMULATION}

\section{Coupled models}

In Figure 1, two plane frames are shown, the structure 1 with $n+m$ floors and the structure 2 with $n$ floors. Each of these buildings has mass, stiffness, and damping properties $m_{l}^{j}, c_{l}^{j}, k_{l}^{j}$ known beforehand, where $i$ indicates the floor number and $j$ the building number. The strategy of passive coupling control involves the placement of springs and dampers between the two buildings, whose mechanical properties are $k_{n}{ }^{3}$ and $c_{n}{ }^{3}$, here $n$ indicates the position of these elements.

\section{STRUCTURE 1}

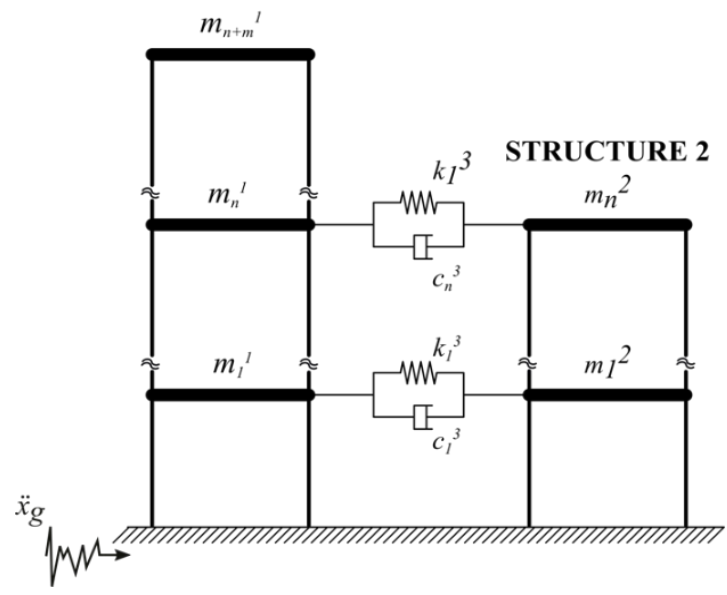

STRUCTURE 1

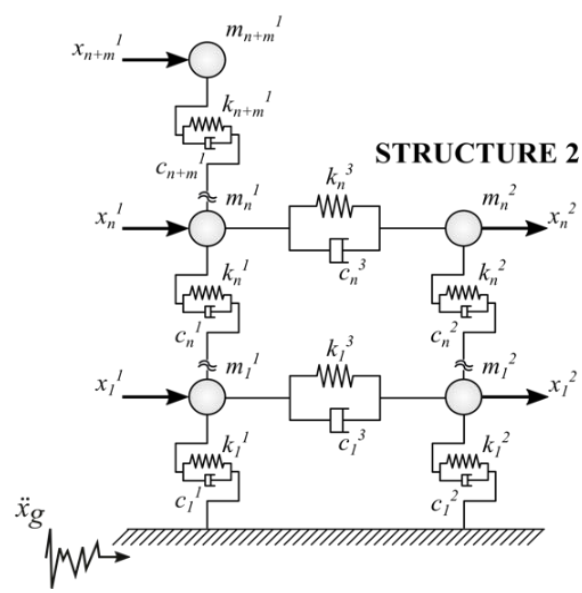

Figure 1. Coupled system with multiple degrees of freedom.

The coupled system motion equation, when submitted to a seismic base acceleration $\ddot{\mathbf{x}}_{g}(t)$ is given by:

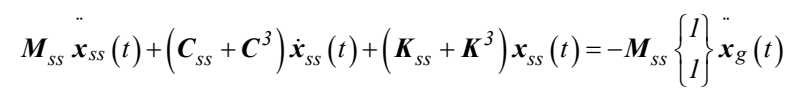

where $\mathbf{M}_{s s}, \mathbf{C}_{s s}$ and $\mathbf{K}_{s s}$ are the mass, damping and stiffness matrices of the coupled system respectively; $\mathbf{C}^{3}$ and $\mathbf{K}^{3}$ are the matrices that contains the damping and stiffness coefficients of the linking system $k_{n}{ }^{3}$ and $c_{n}{ }^{3} ; \mathbf{x}_{s s}(t), \dot{\mathbf{x}}_{s s}(t)$ and $\ddot{\mathbf{x}}_{s s}(t)$ are the vectors containing the displacements, velocities and accelerations of the two structures relative to the ground.

Mass, stiffness and damping matrices, $\mathbf{M}_{\mathrm{ss}}, \mathbf{K}_{\mathrm{ss}}$ and $\mathbf{C}_{\mathrm{ss}}$, of the coupled structure are defined as follows:

$\boldsymbol{M}_{s s}=\left[\begin{array}{cc}\boldsymbol{m}_{(n+m, n+m)}^{1} & O_{(n+m, n)} \\ O_{(n, n+m)} & \boldsymbol{m}_{(n, n)}^{2}\end{array}\right]$

$\boldsymbol{C}_{s S}=\left[\begin{array}{cc}\boldsymbol{c}_{(n+m, n+m)}^{1} & 0_{(n+m, n)} \\ O_{(n, n+m)} & \boldsymbol{c}_{(n, n)}^{2}\end{array}\right]$

$\boldsymbol{K}_{s s}=\left[\begin{array}{cc}\boldsymbol{k}_{(n+m, n+m)}^{l} & 0_{(n+m, n)} \\ O_{(n, n+m)} & \boldsymbol{k}_{(n, n)}^{2}\end{array}\right]$ 
where: $\mathbf{m}^{j}$ is the diagonal mass matrix of the $j$ th building; $\mathbf{c}^{j}$ and $\mathbf{k}^{j}$ are a block diagonal matrix corresponding to the internal damping and stiffness of the $j$ th building. These matrices can be written as:

$\boldsymbol{m}^{j}=\left[\begin{array}{lll}m_{l}^{j} & & \\ & \ddots & \\ & & m_{i}^{j}\end{array}\right]$

$\boldsymbol{c}^{j}=\left[\begin{array}{cccccc}c_{1}^{j}+c_{2}^{j} & -c_{2}^{j} & & & & \\ -c_{2}^{j} & c_{2}^{j}+c_{3}^{j} & -c_{3}^{j} & & & \\ & -c_{3}^{j} & \ddots & & & \\ & & & -c_{i-1}^{j} & c_{i-1}^{j}+c_{i}^{j} & -c_{i}^{j} \\ & & & & -c_{i}^{j} & c_{i}^{j}\end{array}\right]$

$\boldsymbol{k}^{j}=\left[\begin{array}{cccccc}k_{1}^{j}+k_{2}^{j} & -k_{2}^{j} & & & & \\ -k_{2}^{j} & k_{2}^{j}+k_{3}^{j} & -k_{3}^{j} & & & \\ & -k_{3}^{j} & \ddots & & & \\ & & & -k_{i-1}^{j} & k_{i-1}^{j}+k_{i}^{j} & -k_{i}^{j} \\ & & & & -k_{i}^{j} & k_{i}^{j}\end{array}\right]$

where $j$ indicates the structure number, $m_{l}^{j}, c_{l}^{j}$ and $k_{l}^{j}$ are the mass, damping and stiffness value of the $i$ th story in the $j$ th building. The matrix that contains the damping coefficients of the linking system $\mathbf{C}^{3}$ is:

$\boldsymbol{C}^{3}=\left[\begin{array}{cc}\hat{\boldsymbol{c}}_{(n+m, n+m)}^{l} & -\hat{\boldsymbol{c}}_{(n+m, n)} \\ -\hat{\boldsymbol{c}}_{(n, n+m)} & \hat{\boldsymbol{c}}_{(n, n)}^{2}\end{array}\right]$

where

$\hat{\boldsymbol{c}}_{(n+m, n+m)}^{I}=\left[\begin{array}{ccccc}c_{1}^{3} & & & & \\ & \ddots & & & \\ & & c_{n}^{3} & & \\ & & & \ddots & \\ & & & & 0\end{array}\right], \hat{\boldsymbol{c}}_{(n, n)}^{2}=\left[\begin{array}{ccc}c_{1}^{3} & & \\ & \ddots & \\ & & c_{n}^{3}\end{array}\right]$

$\hat{\boldsymbol{c}}_{(n, n+m)}=\left[\begin{array}{ccccc}c_{I}^{3} & & & \ldots & 0 \\ & \ddots & & \cdots & 0 \\ & & c_{n}^{3} & \cdots & 0\end{array}\right], \hat{\boldsymbol{c}}_{(n+m, n)}=\left[\begin{array}{cccc}c_{I}^{3} & & \\ & \ddots & \\ & & c_{n}^{3} \\ \vdots & \vdots & \vdots \\ 0 & 0 & 0\end{array}\right]$

where $c_{n}{ }^{3}$ is the damping coefficient of the nth passive linking element. The matrix that contains the stiffness coefficients of the linking system $\mathbf{K}^{3}$ can be obtained from Equation 8, replacing the damping coefficients ${c_{n}}^{3}$ by the corresponding stiffness coefficients $k_{n}{ }^{3}$.

From the second-order model (Equation 1), a first-order state-space model can be derived: 
$\left\{\begin{array}{c}\dot{\boldsymbol{z}}(t)=\boldsymbol{A z}(t)+\boldsymbol{E} \boldsymbol{x}_{g}(t) \\ \boldsymbol{y}(t)=\boldsymbol{C}_{y} \boldsymbol{z}(t)\end{array}\right.$

with state vector:

$z(t)=\left\{\begin{array}{l}x(t) \\ \dot{x}(t)\end{array}\right\}$

The state and disturbance input matrices, $\mathbf{A}$ and $\mathbf{E}$, in Equation 11 have, respectively, the following form:

$$
\boldsymbol{A}=\left[\begin{array}{cc}
0 & \boldsymbol{I} \\
-\boldsymbol{M}^{-1} \boldsymbol{K} & -\boldsymbol{M}^{-1} \boldsymbol{C}
\end{array}\right], \boldsymbol{E}=\left\{\begin{array}{c}
0 \\
-1
\end{array}\right\}
$$

Obtained the state vector $\mathbf{z}(t)$ and using the output matrix $\mathbf{C}_{y}$ shown in Equation 14, the vector $\mathbf{y}(t)$ (Equation 15) can be obtained, which contains the responses in terms of displacement and velocity relative to the ground, as well as the absolute acceleration of the two buildings.

$\boldsymbol{C}_{y}=\left[\begin{array}{cc}\boldsymbol{I} & 0 \\ 0 & \boldsymbol{I} \\ -\boldsymbol{M}_{e e}^{-1} \boldsymbol{K}_{e e} & -\boldsymbol{M}_{e e}^{-1} \boldsymbol{C}_{e e}\end{array}\right]$

$\boldsymbol{y}(t)=\left\{\begin{array}{c}\boldsymbol{x}_{e e}(t) \\ \dot{\boldsymbol{x}}_{e e}(t) \\ - \\ \boldsymbol{x}_{e e}(t)\end{array}\right\}$

\section{Correlation between numerical and experimental data}

Correlation methods are some techniques to compare the analytical modal data with the experimental modal data. Among the most used correlation techniques are the FER frequency variation and the Modal Assurance Criterion (MAC) [39], [40].

The correlation between natural frequencies is calculated using the FER frequency variation. The FER index for the $g$ experimental mode is calculated using Equation 16, where $\lambda_{h}$ and $\lambda_{g}$ are the numerical and experimental natural frequency of the $h$ and $g$ mode, respectively.

$$
F E R=\left|\frac{\lambda_{h}-\lambda_{g}}{\lambda_{g}}\right|
$$

The agreement between numerical and experimental modes of vibration is obtained through the Modal Assurance Criterion (MAC) index [39], [40]:

$$
\operatorname{MAC}(g, h)=\frac{\left|\boldsymbol{\Phi}_{g}^{T} \boldsymbol{\Phi}_{h}\right|^{2}}{\left(\boldsymbol{\Phi}_{h}^{T} \boldsymbol{\Phi}_{h}\right)\left(\boldsymbol{\Phi}_{g}^{T} \boldsymbol{\Phi}_{g}\right)}
$$


where $\boldsymbol{\Phi}_{g}$ and $\boldsymbol{\Phi}_{h}$ are the test modal and analytical modal vectors, respectively. The MAC index takes values between 0 (representing no consistent correspondence) and 1 (representing a consistent correspondence). Values larger than 0.9 indicate consistent correspondence whereas small values indicate poor resemblance of the two shapes [43].

\section{Numerical and experimental models}

Six modules were constructed as shown in Figure 2a and represent a common floor of a residential building. Each of these modules consists of two stainless steel columns (ferritic alloy $430-\mathrm{E}=210 \mathrm{GPa}$ ) with a rectangular section $(1.5 \times 25.4 \mathrm{~mm})$ and rigid aluminum beams with a rectangular section $(25.4 \times 9.8 \mathrm{~mm})$. The height of the columns was considered of $200 \mathrm{~mm}$ [31].

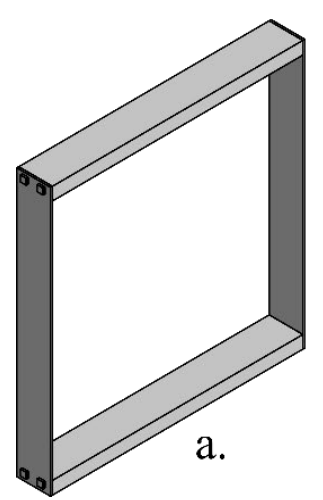

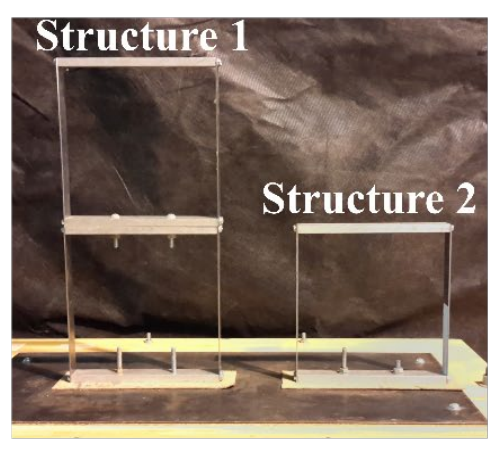

b.

\section{Structure 1}

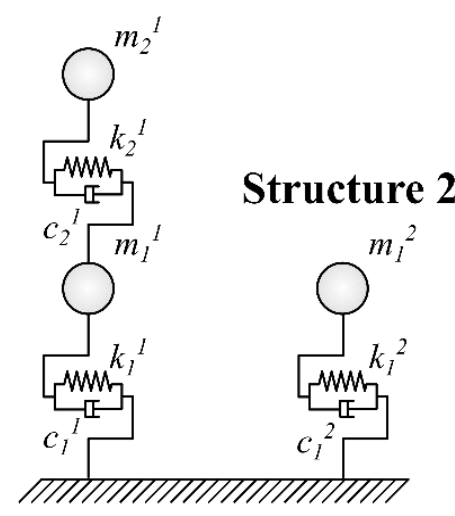

c.

Figure 2. a) module of the plane frame; b) experimental model of adjacent uncoupled plane frames; c) numerical model of adjacent uncoupled plane frames.

By joining several of these modules, it is possible to simulate more pavement structures as if they were a shear building (Figure 2b), since the stiffness of the aluminum bars, which constitute the floors, is much higher in relation to the stainless- steel plates stiffness, which represent the columns of the experimental models. In Figure 2c, the numerical models of adjacent uncoupled plane frames are presented.

The mass and stiffness matrices of the models showed in the Figure $2 \mathrm{c}$ are defined in the following Equations 18 and 19. In the mass matrices, besides the mass of the elements that make up the modules, the masses of the screws, nuts and washers used to join them were considered. In the case of stiffness matrices, it was considered that the stiffness of the modules is given by the columns fixed at the base.

$$
\begin{gathered}
\boldsymbol{m}^{l}=\left[\begin{array}{cc}
0,3912 & 0 \\
0 & 0,1826
\end{array}\right] \mathrm{kg} \\
m_{l}^{2}=0,1830 \mathrm{~kg} \\
\boldsymbol{k}^{l}=\left[\begin{array}{cc}
9740,27 & -4885,93 \\
-4885,930 & 4885,93
\end{array}\right] \frac{\mathrm{N}}{M} \\
k_{l}^{2}=5236,19 \frac{\mathrm{N}}{M}
\end{gathered}
$$


To assemble the stiffness matrices, the Caughey or extended Rayleigh method [44] (Equation 20) was used to construct these matrices from data obtained from experimental modal analysis of both buildings, that is, from a natural frequency $\omega_{i}$ and its corresponding modal damping $\xi_{i}$ of the $i$ th mode.

$$
\boldsymbol{c}=\boldsymbol{m} \sum_{i=0}^{N-1} \alpha_{i}\left(\boldsymbol{m}^{-1} \boldsymbol{k}\right)^{i}
$$

In Equation 20: $N$ is the number of degrees of freedom of the system; $\mathbf{m}$ and $\mathbf{k}$ are the mass and stiffness matrices of the building, respectively; $\alpha_{i}$ are real and positive constants which are calculated by:

$$
\xi_{n}=\frac{1}{2} \sum_{i=0}^{j-1} \alpha_{i}\left(\omega_{n}\right)^{2 i-1}
$$

where $\xi_{n}$ e $\omega_{n}$ are the natural frequencies and damping factors for the $\mathrm{n}$ modes of the system. Thus, the equation above becomes a set of equations, one for each $\omega_{n}$ and $\xi_{n}$, where $\alpha_{i}$ is the constant to be calculated.

\section{Shaking Table}

In order to simulate the movement at the base of the small-scale models, the unidirectional shaking table shown in Figure 3 was designed and constructed in the Laboratory of Structures of the University of Brasilia according to the safety conditions of the Brazilian technical standards.
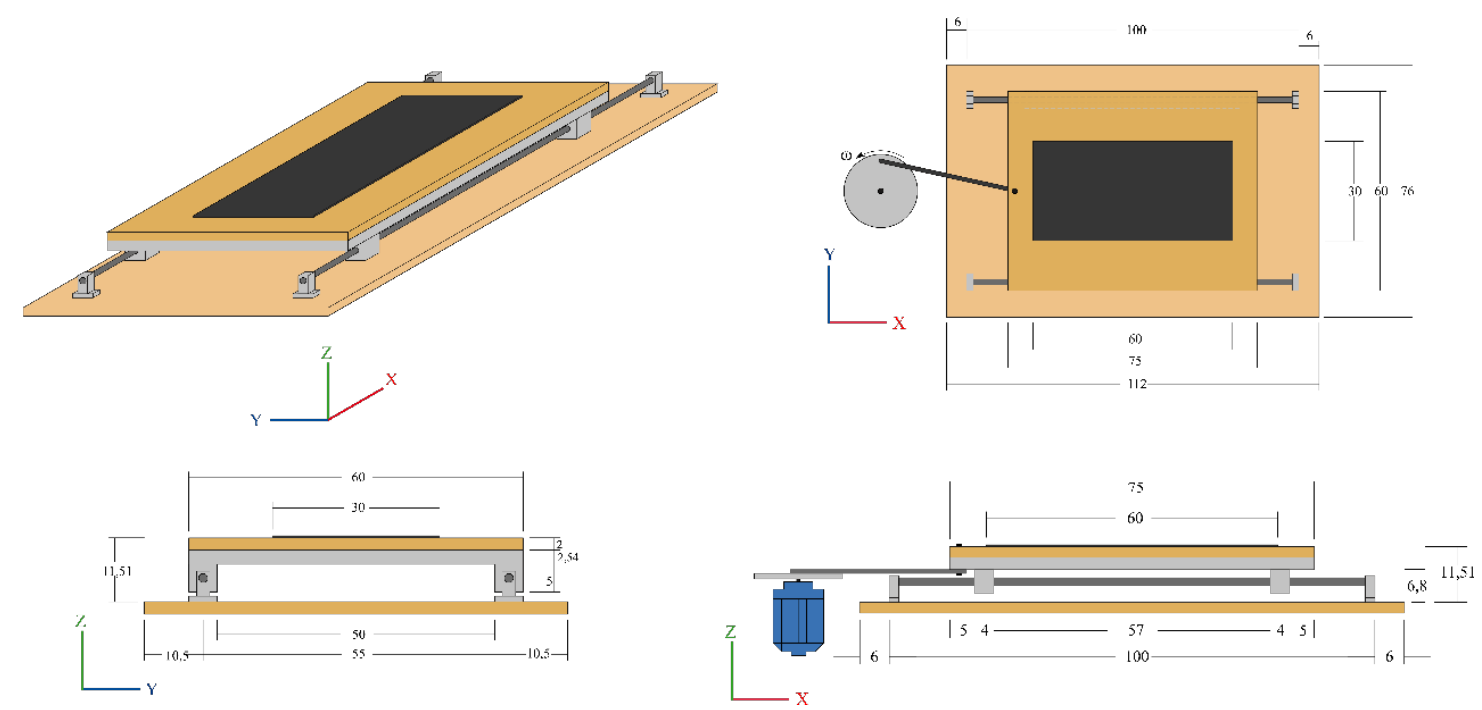

Figure 3. Unidirectional shaking table. Dimensions in centimeters.

The oscillating motion of the table is generated by a rod-crank system, which can transform the circular movement into a translational movement. The crank describes the flat rotational movement, the rod pushes the main platform which, by means of the four linear bearings located in its corners, has rectilinear translation motion in the orthogonal direction X. The rotation movement of the crank is promoted by a motor whose angular rotation speed $\omega$ is controlled by a frequency inverter. The constructed model and mechanical and electronic components of the Shaking table can be observed in Figure 4. 


\section{Instrumentation}

To obtain the accelerations in the plane frames, as well as their modal identification, PCB Piezotronics model 353B01 accelerometers were used, which have an approximate mass of $10 \mathrm{~g}$ and sensitivity of $\pm 5 \% 20 \mathrm{mV} / \mathrm{g}$ $\left(2.04 \mathrm{mV} /\left(\mathrm{m} / \mathrm{s}^{2}\right)\right)$. These accelerometers were connected to the IPC Model 482A22 unit gain signal conditioner from the same company and which translates the vibration of the structure into electrical pulses and sends them to the ADS2000 signal receptor, manufactured by Lynx Tecnologia Eletrônica. Finally, the acceleration registers are monitored and recorded using AqDados 7 software [45].

The acquisition equipment was configured to capture records from 1 to 3 channels, at time instants of $0.005 \mathrm{~s}$, resulting in a $200 \mathrm{~Hz}$ sampling frequency. Consequently, the Nyquist frequency was half the sampling frequency, in this case, $100 \mathrm{~Hz}$.

a.

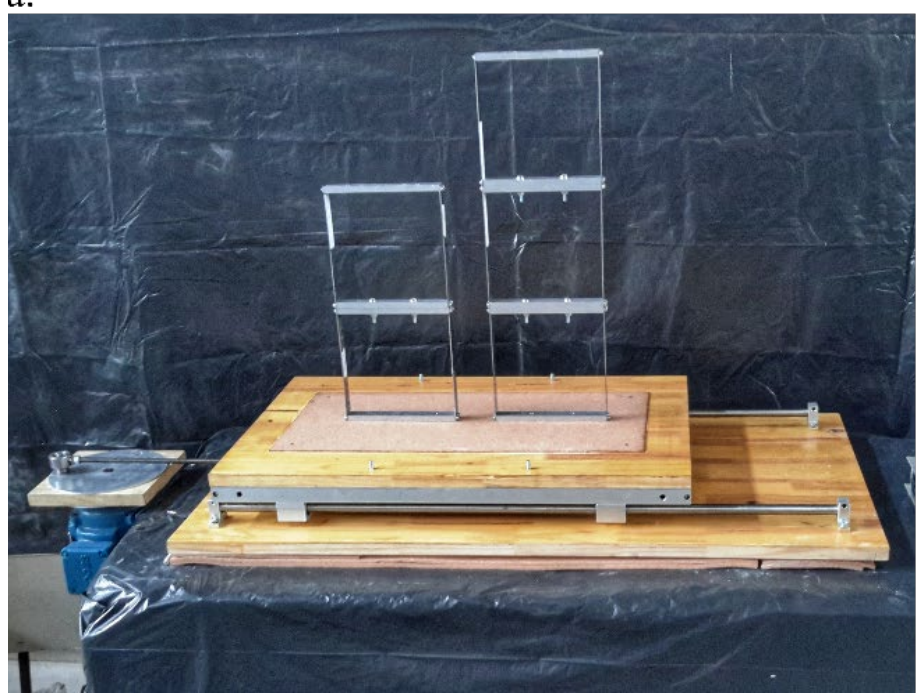

b.
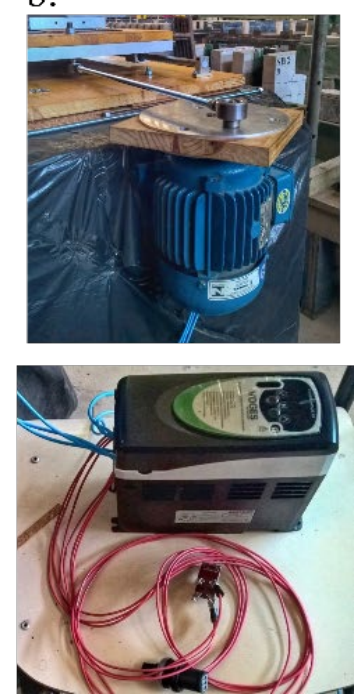

Figure 4. Shaking table built and mechanical and electronic components.

\section{RESULTS}

\section{Plane frame modal identification}

Table 1 shows the natural frequencies obtained from the acceleration records acquired in the laboratory for each plane frame model (Figure $2 b$ ), as well as the FER frequency variation and the damping factor $\xi$ for each vibration mode. The comparison of the numerical and experimental vibration modes of Structure 1 (Figure 2b), as well as the matrix of the MAC index correlation, are shown in Figure 5.

It can be seen in the Table 1 that the first frequencies in both plane frames presented a FER index lower than 1\%. However, there was a low value for the second frequency, with differences of more than $7 \%$. On the other hand, it is observed in Figure 5 that the MAC indexes presented diagonal values approximately equal to 1, which indicates a good agreement between the modal forms.

It is interesting to note that, as expected, the damping factors presented very low values as seen in the Table 1 [46]. Thus, having the frequencies and damping factors and using Equations 20 and 21, the damping matrices of the structures shown in Figure $2 \mathrm{~b}$ can be assembled.

Finally, it is worth noting that the $1 \%$ error between the numerical and experimental frequencies for the first mode (fundamental mode) is acceptable due to the possible differences that the shear building model or plane frame are unable to represent, besides the possible instrumental errors. Thus, it was decided to not be updating the models. 


\section{Connection Device}

An optimization study was performed using the particle swarm optimization (PSO) [41] in a way to set the mechanical properties $k_{n}{ }^{3}$ and $c_{n}{ }^{3}$ of the connection device (Figure 1). The summation of coupled model rms (Root Mean Square) accelerations was used as an objective function. Once these mechanical properties were obtained, the damper that was used in the experimental tests was built. Table 2 presents the results of the optimization.

It can be observed in Table 2 that $k^{3}$ and $c^{3}$ had a very little variation. It also can be noticed that to control dynamic response on both structures, it is necessary to use a connection device with $c^{3}=9.48 \mathrm{Ns} / \mathrm{m}$ and $k^{3}=0$. It can be said that the best connection device to the analyzed model is using only a viscofluid damper

Table 1. Averages values of experimental vibration natural frequencies and damping factors of the plane frames, as well as the FER index.

\begin{tabular}{|c|c|c|c|c|c|}
\hline Structure & Mode & $\xi$ & Exp. Frequency [Hz] & Num. Frequency [Hz] & FER [\%] \\
\hline \multirow{2}{*}{1} & 1 & 0.40 & 13.90 & 13.84 & 0.45 \\
\hline & 2 & 0.20 & 36.18 & 33.42 & 7.62 \\
\hline 2 & 1 & 0.20 & 27.34 & 27.11 & 0.84 \\
\hline
\end{tabular}
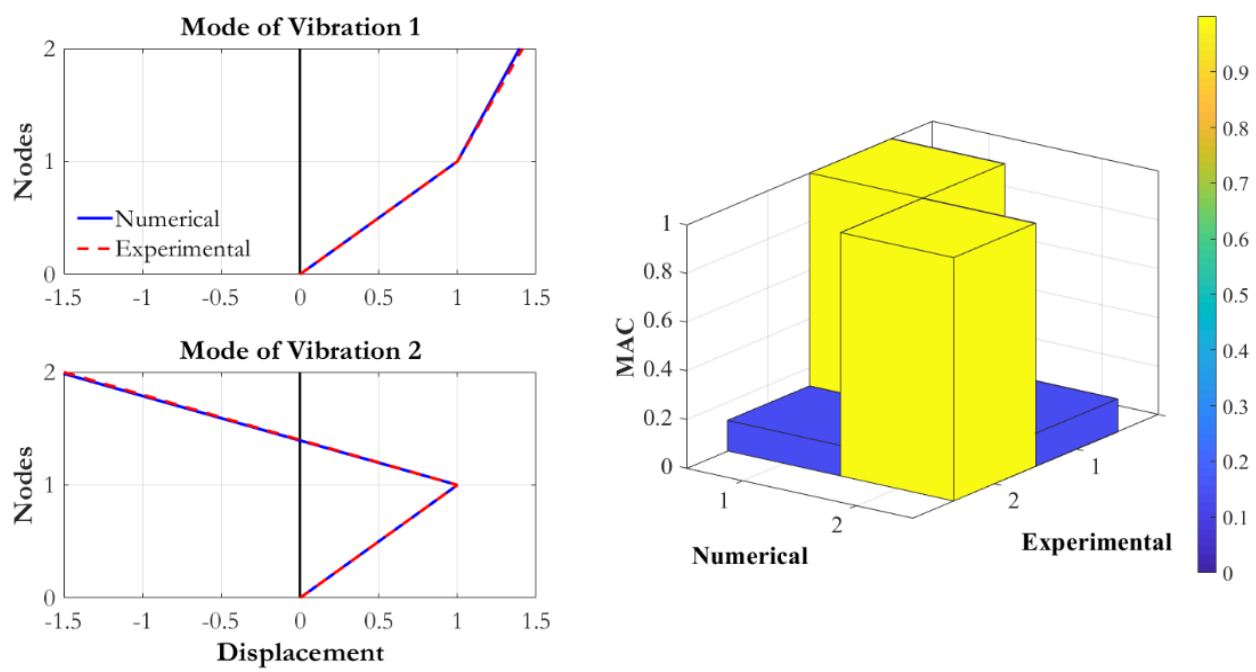

Figure 5. Comparison of numerical and experimental vibration modes and MAC correlation matrix - Structure 1 Uncoupled.

Table 2. Optimal connection device properties obtained with PSO.

\begin{tabular}{ccc}
\hline$c_{n}{ }^{3}[\mathrm{Ns} / \mathrm{m}]$ & $\boldsymbol{k}_{n}{ }^{3}[\mathrm{~N} / \mathrm{m}]$ & $\boldsymbol{f}_{\text {objetivo }}\left[\mathrm{m} / \mathrm{s}^{2}\right]$ \\
\hline 9.4799 & $9.58930 \times 10^{-7}$ & 1.7197 \\
\hline 9.4798 & $8.58930 \times 10^{-7}$ & 1.7197 \\
\hline 9.4788 & $9.18925 \times 10^{-7}$ & 1.7197 \\
\hline
\end{tabular}

\section{Viscofluid damper construction}

The connecting element used in this work was of the viscofluid type $\left(c^{3} \neq 0, k^{3}=0\right)$ as shown in Figure 6 . In this type of shock absorber, the energy dissipation occurs due to the rub of the piston in crossing the fluid generated by the viscous fluid, defined as viscous friction. The piston restricts the flow of oil through holes when it moves, causing a dissipation of mechanical energy in the form of heat. 
a.

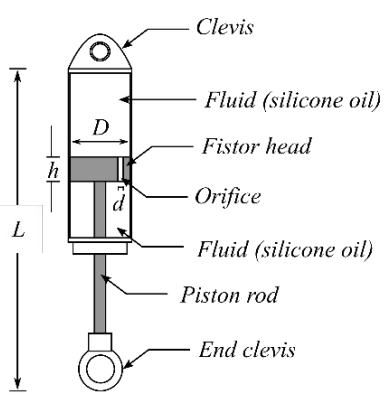

b.

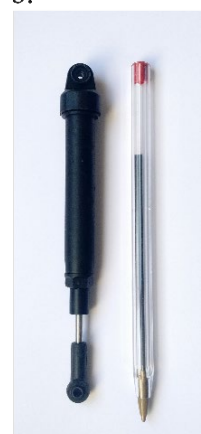

Figure 6. a) Components of a viscofluid damper; b) Viscofluid damper used in the experimental analyses.

As the piston rod moves within the cylinder (Figure 6a), the fluid exerts a resistive force proportional to the velocity. The simplest mathematical modeling of the damping force, adopted in this work, is given by Equation 22 , where $F_{d}$ is the viscous resistance or damper force, $\mathrm{c}^{3}$ is the viscous damping coefficient of the connecting element and $\dot{x}$ is the relative velocity.

$F_{d}=c^{3} \dot{x}$

For the calculation of the coefficient $c^{3}$, it is generally used Equation 23 proposed by Rao [47]:

$c^{3}=\mu \frac{3 \pi D^{3} h}{d^{3}}\left(1+\frac{2 d}{D}\right)$

where: $\mu$ is the dynamic viscosity of the fluid; $D$ and $h$ are the diameter and height of the fistor head, respectively; $d$ is the diameter of the orifice in the fistor head. For the construction of this device, the measurements listed in Table 3 were employed.

Table 3. Geometric properties of the fluid viscous damper.

\begin{tabular}{cccc}
\hline$L[\mathrm{~mm}]$ & $D[\mathrm{~mm}]$ & $d[\mathrm{~mm}]$ & $h[\mathrm{~mm}]$ \\
\hline 200 & 10 & 1 & 3 \\
\hline
\end{tabular}

Having calculated the optimal $c^{3}$ value of the connection element and using the geometric properties of the fluid viscous damper (Table 3) as well as Equation 23, it is possible to obtain the dynamic viscosity $\mu$ of the fluid to be placed in the device. Thus, $\mu=0.279$ Pa.s was obtained.

In this work, silicone oils were used, which are common in the manufacture of shock absorbers for RC cars. However, an oil with dynamic viscosity slightly higher than that calculated was used due to the unavailability on the market for the purchase of oils. Therefore, it was used a $47 \mathrm{~V} 350$ silicone oil [48] of $0.97 \mathrm{~g} / \mathrm{cm}^{3} \mathrm{density}$ and a dynamic viscosity $\mu=0.350$ Pa.s. Table 4 shows the mechanical properties, ideal and used, of the viscofluid damper.

Table 4. Mechanical properties of the viscofluid damper.

\begin{tabular}{cccc}
\hline$\mu_{\text {ideal }}[$ Pa.s $]$ & $c^{3}$ ideal $[\mathrm{Ns} / \mathrm{m}]$ & $\mu_{\text {used }}[\mathrm{Pa} . \mathrm{s}]$ & $\mathrm{c}^{3}$ used $[\mathrm{Ns} / \mathrm{m}]$ \\
\hline 0.279 & 9.48 & 0.350 & 11.519 \\
\hline
\end{tabular}

\section{Dynamic responses}

This section presents the comparison between the experimental and numerical responses of the plane frames shown in Figure 7 , without and with coupling, when submitted to base movement. For each case, ten tests were performed, five for the uncoupled system and five for the coupled system, in order to calculate an average of the responses and decrease the error tendency. 

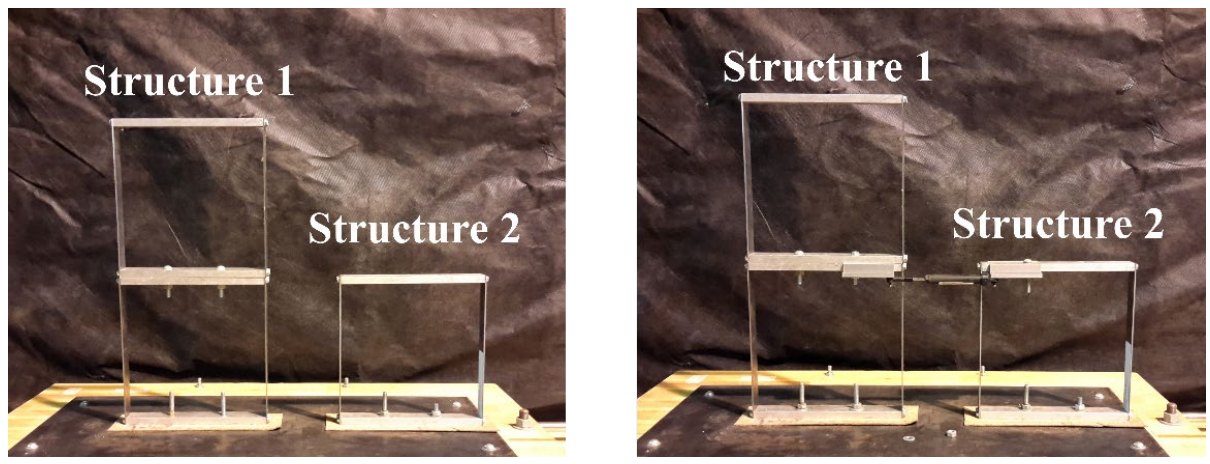

Figure 7. a) Uncoupled frames; b) Coupled frames.

Generally, in the study of the coupling technique, the acceleration records of El Centro, Kobe and Northridge earthquakes are used, which present the highest values of peak ground acceleration (PGA) in a frequency range between 2 and $5 \mathrm{~Hz}$. Thus, in this work, a movement in the base with an oscillation frequency of $3 \mathrm{~Hz}$ was used (Figure 8), which represents the average of these frequency range. This simplification is necessary to be able to compare numerical and experimental results.

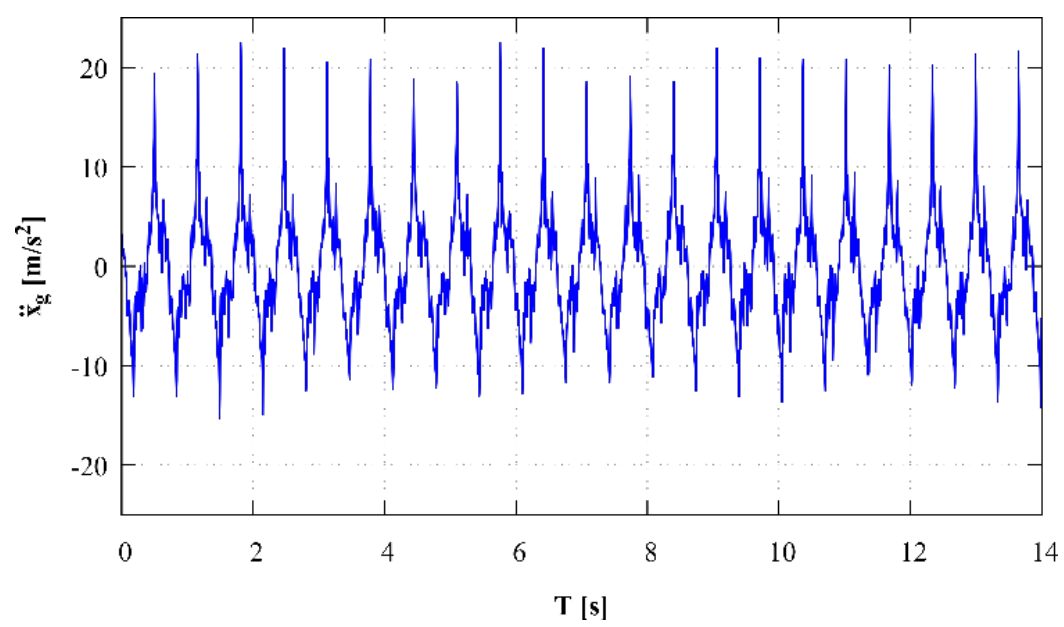

Figure 8. Acceleration records measured at the base of the adjacent experimental plane frames.

Figures 9 and 10 show the acceleration records at different points calculated using Equation 11 and those obtained in experimental tests, respectively. With the acceleration register it was possible to calculate the rms responses (Table 5), which, when compared, gives an indication of the effectiveness of the coupling technique in reducing dynamic responses [10]. Likewise, using these acceleration registers it was possible to obtain the frequency spectra, shown in Figures 11 and 12. It should be noted that these frequency spectra and the rms values listed in Table 5 show the mean of the data collected from all tests.

It can be seen from Figures 9 and 10 and Table 5 that, by coupling the structures with the viscofluid damper, it was possible to considerably decrease the accelerations in Structure 1 (red lines) compared to the uncoupled structure (gray lines). On the other hand, in Structure 2, even having a fundamental frequency $(27.34 \mathrm{~Hz})$ well above the value of the excitation frequency $(3 \mathrm{~Hz})$, the coupling technique managed to slightly decrease the accelerations compared to the uncoupled structure.

It can be seen in Figures 11 and 12 that the numerical and experimental spectra were almost identical, displaying differences only in the amplitude values at the peak frequency of the structures. Similarly, it is observed that the frequency spectra of the coupled system (red lines) decreased in the peaks where the fundamental frequency of each structure appears without increasing or decreasing the frequency of the structures. 
In the case of the frequency spectra of Structure 2 (Figures 11 and 12), it is observed that in some ranges of the frequency spectrum there is an increase of the amplitudes when this building is coupled, however, these peaks correspond to harmonics associated to the movement of the shake table.

Finally, it is noteworthy that even without updating the numerical models, it was obtained response values close to those reached experimentally, and the structure 1 presented the closest approximation between the results.

Table 5. Mean of rms experimental and numerical responses in terms of acceleration.

\begin{tabular}{|c|c|c|c|c|c|c|}
\hline \multirow{3}{*}{$\begin{array}{c}\text { Coupling } \\
\text { Configurations }\end{array}$} & \multicolumn{4}{|c|}{ Structure $1-r m s ~\left[m / s^{2}\right]$} & \multicolumn{2}{|c|}{ Structure $2-r m s ~\left[m / s^{2}\right]$} \\
\hline & \multicolumn{2}{|c|}{ Numerical } & \multicolumn{2}{|c|}{ Experimental } & Numerical & Experimental \\
\hline & $1^{\text {st }}$ floor & Top & $1^{\text {st }}$ floor & Top & Top & Top \\
\hline Uncoupled & 36.93 & 48.36 & 31.35 & 44.36 & 11.49 & 11.11 \\
\hline Coupled & 9.18 & 13.49 & 9.85 & 15.21 & 9.89 & 10.03 \\
\hline$\%$ Reduction & 75.1 & 72.1 & 68.6 & 65.7 & 13.9 & 9.7 \\
\hline
\end{tabular}

\section{Numerical Results}
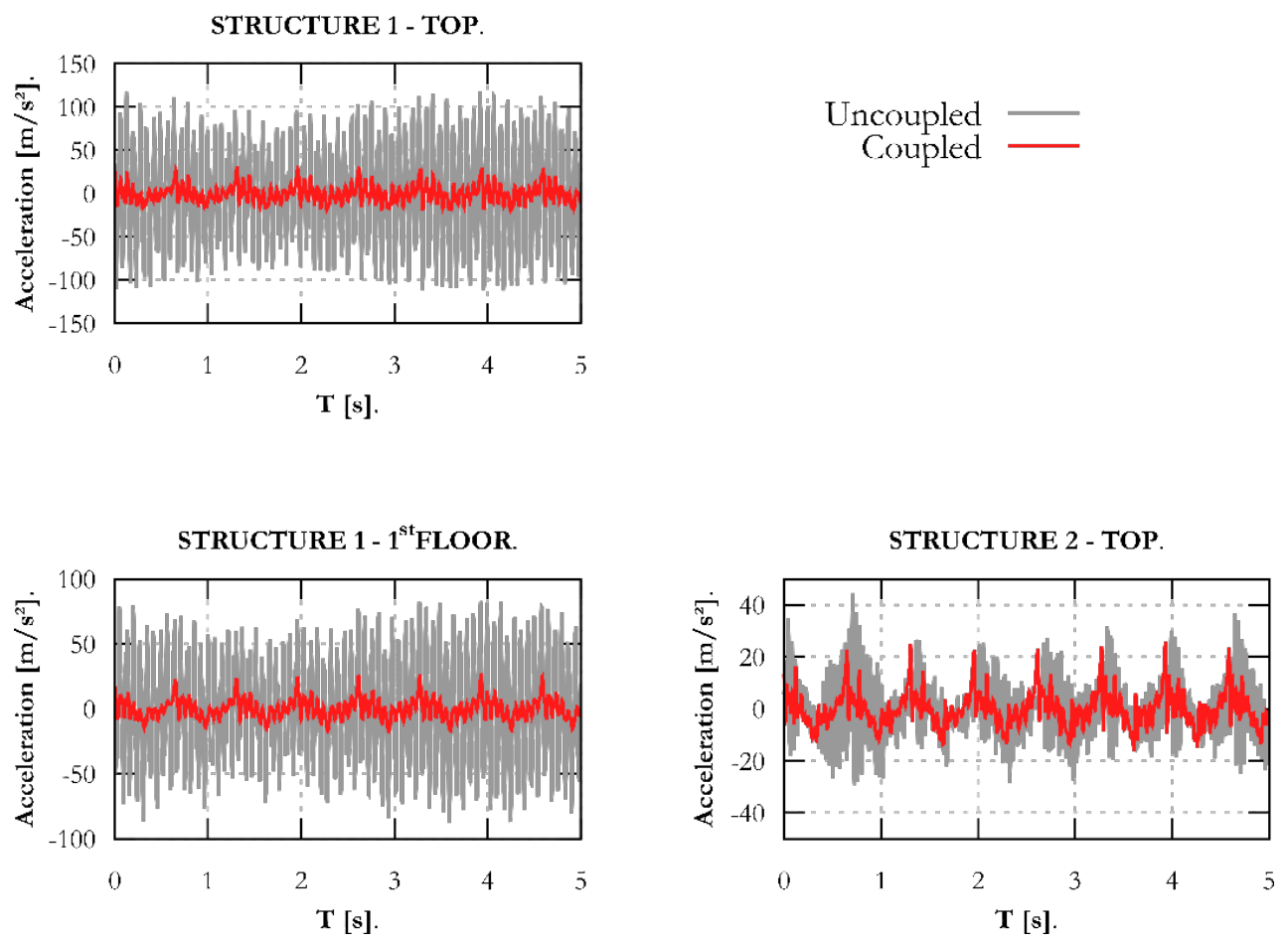

Figure 9. Comparison of the numerical acceleration records of the adjacent frames. 


\section{Experimental Results}

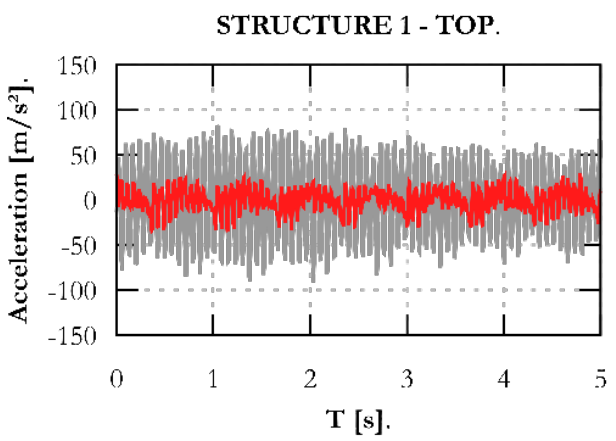

\section{Uncoupled}

Coupled

STRUCTURE 1 - $1^{\text {st }}$ FLOOR

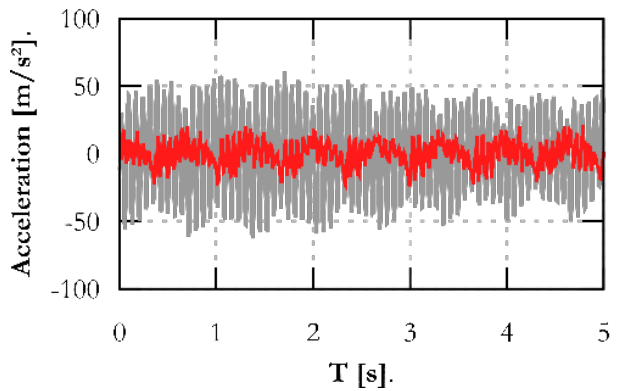

STRUCTURE 2 - TOP.

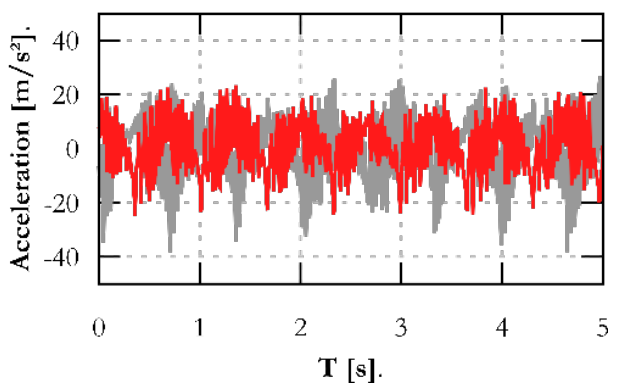

T [s].

Figure 10. Comparison of the experimental acceleration records of the adjacent frames.

\section{Numerical Results}

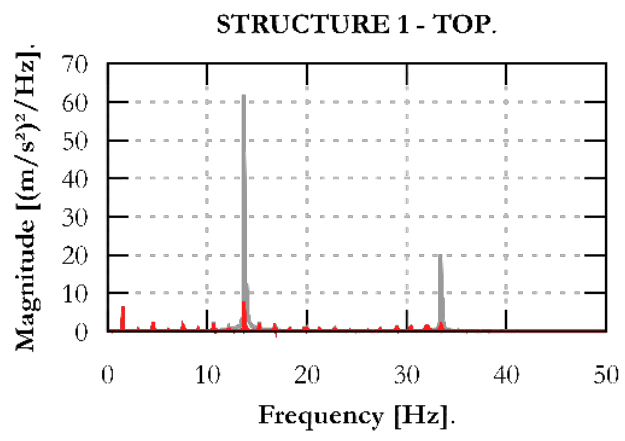

Uncoupled Coupled
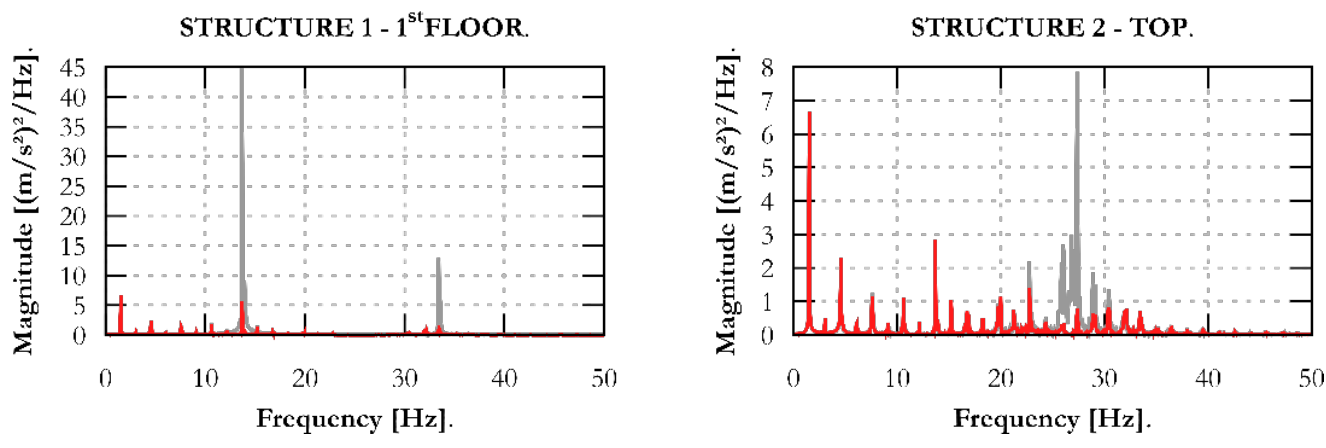

Figure 11. Comparison of the numerical frequency spectra of the adjacent frames. 


\section{Experimental Results}
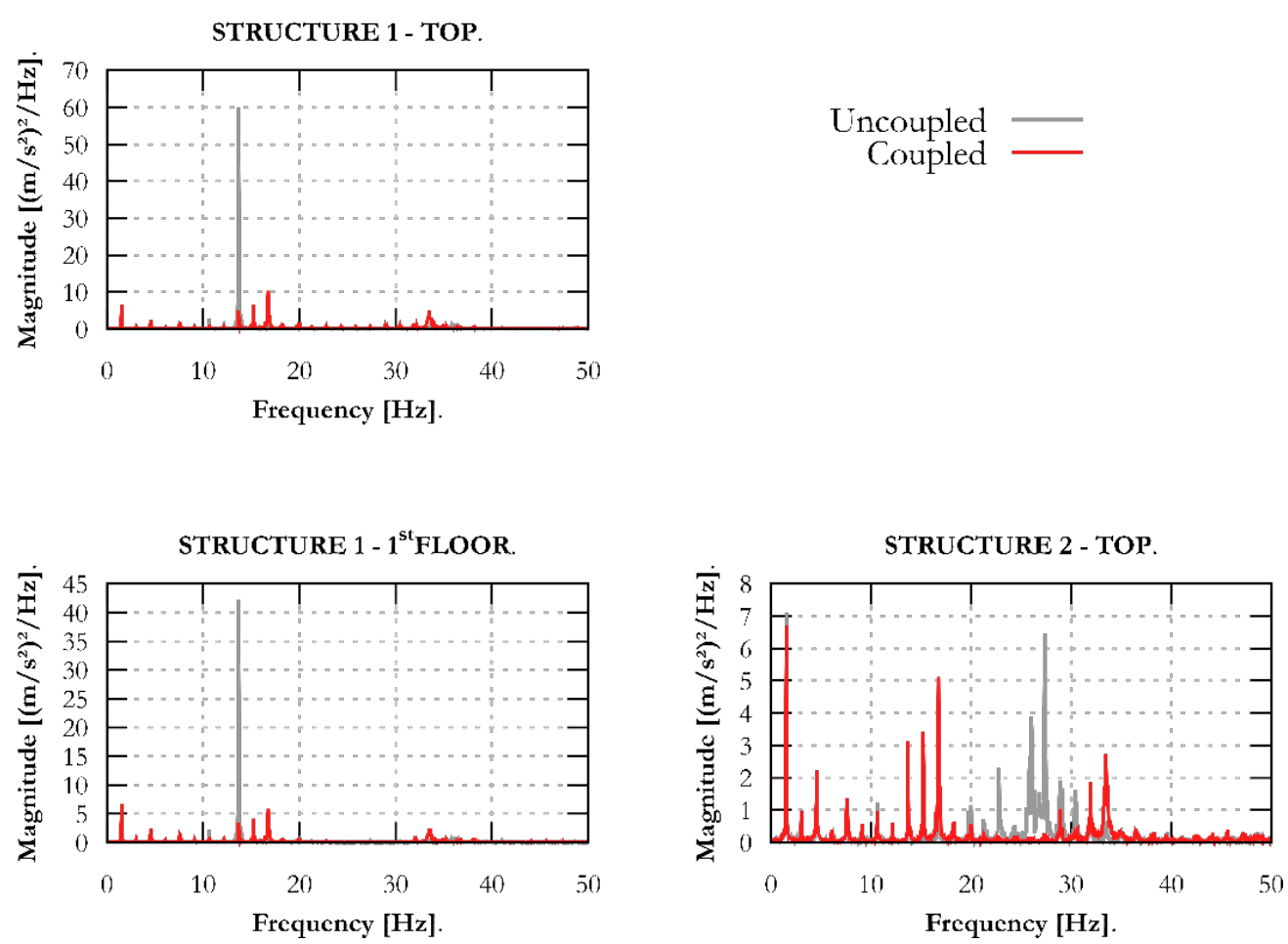

Figure 12. Comparison of the experimental frequency spectra of the adjacent frames.

\section{CONCLUSION}

The structural coupling technique consists of connecting two or more neighboring buildings by means of coupling devices in order to provide reaction control forces and thus, reduce the dynamic effects. Doing that, at first, it is possible to control the response of both structures simultaneously, which is precisely the attractiveness of the technique.

It is important to note that in this work, a base movement with an oscillation with only one frequency component $(3 \mathrm{~Hz})$ was used that represents the average of the frequencies range of the earthquakes most considered in research on the coupling technique.

Based on the results obtained in this work, several conclusions can be drawn. The optimization results showed that the fluid viscous damper is the ideal connection device, since increases the damping of the coupled structures and did not interfere in the values of the frequencies of the coupled system.

Another aspect to mention is that, even though the oil with the optimum dynamic viscosity was not used due to the unavailability of the material (common situation in civil construction), there was a decrease in the peak values of the acceleration records as well as in the amplitude peaks in the frequency spectra.

Finally, it is important to note that this research can be adapted for concrete or steel buildings [1], [15], [36]. The mathematical formulation would be the same, however, it would change the values of the mechanical properties of the structures.

\section{ACKNOWLEDGEMENTS}

The authors acknowledge CNPq Brazilian Council of National Scientific and Technological Development and Federal District Research Support Foundation (FAPDF) for the financial support of this research.

\section{REFERENCES}

[1] T. Watanabe, K. Seto, H. Toyoda, and T. Takano, "Bidirectional connected control method applied to an experimental structural model split into four substructures," J. Phys. Conf. Ser., vol. 744, no. 1, pp. 12-35, Sep 2016., http://dx.doi.org/10.1088/1742$6596 / 744 / 1 / 012035$. 
[2] K. Seto "Vibration control method for flexible structures arranged in parallel," in Proc. 1st World Conf. Struct. Control, vol. 2, 1994, FP3-62-71.

[3] K. Fujimura, K. Makita, T. Watanabe, and K. Seto, "Vibration control using connected control device for two identical structures arranged in parallel," in Proc. ASME 2005 Int. Des. Eng. Tech. Conf. Comput. Inf. Eng. Conf., 2005, pp. 2357-2364, http://dx.doi.org/10.1115/DETC2005-85194.

[4] R. E. Klein, C. Cusano, and J. Stukel, "Investigation of a method to stabilize wind induced oscillations in large structures," in 1972 ASME Winter Annu. Meeting (Paper 72), 1972.

[5] M. Kunieda, "Earthquake prevent design and earthquake proof design for structures," J. JSME, vol. 79, no. 689, pp. 86-91, 1974.

[6] B. D. Westermo, "The dynamics of interstructural connection to prevent pounding," J. Earthq. Eng. Struct. Dyn., vol. 18, no. 5, pp. 687-699, 1989., http://dx.doi.org/10.1002/eqe.4290180508.

[7] M. C. Graham, "Design strategies for coupling buildings,” M.S. thesis, Dept. Civ. Environ. Eng., Inst. Technol., Massachusetts, 1994.

[8] J. E. Luco and C. P. Barros, "Optimal damping between two adjacent elastic structures," J. Earthq. Eng. Struct. Dyn., vol. 27, no. 7, pp. 649-659, 1998., http://dx.doi.org/10.1002/(SICI)1096-9845(199807)27:7<649::AID-EQE748>3.0.CO;2-5.

[9] Y. Xu, Q. He, and J. M. Ko, "Dynamic response of damper-connected adjacent buildings under earthquake excitation," J. Eng. Struct., vol. 21, no. 2, pp. 135-148, 1999., http://dx.doi.org/10.1016/S0141-0296(97)00154-5.

[10] R. E. Christenson, "Semiactive control of civil structures for natural hazard mitigation: analytical and experimental studies," Ph.D. dissertation, Dept. Civ. Eng. Geol. Sci., Univ. Notre Dame, Indiana, 2001.

[11] S. H. Kim, S. W. Lee, and H. S. Mha, "Dynamic behaviors of the bridge considering pounding and friction effects under seismic excitation," J. Struct. Eng. Mech., vol. 10, no. 6, pp. 621-633, 2001, http://dx.doi.org/10.12989/sem.2000.10.6.621.

[12] H. Zhu, Y. Wen, and H. Iemura, "A study on interaction control for the seismic response of parallel structures," J. Comp. Struct., vol. 79, no. 1, pp. 231-242, 2001., http://dx.doi.org/10.1016/S0045-7949(00)00119-X.

[13] Y. L. Xu, Z. Yang, and X. L. Lu, "Inelastic seismic response of adjacent buildings linked by fluid dampers," J. Struct. Eng. Mech, vol. 15, no. 5, pp. 513-534, 2003., http://dx.doi.org/10.12989/sem.2003.15.5.513.

[14] C. G. Karayannis and M. J. Favvata, "Inter-story pounding between multistory reinforced concrete structures," J. Struct. Eng. Mech., vol. 20, no. 5, pp. 505-526, 2005., http://dx.doi.org/10.12989/sem.2005.20.5.505.

[15] K. Makita, R. E. Christenson, K. Seto, and T. Watanabe, "Optimal design strategy of connected control method for two dynamically similar structures," J. Eng. Mech., vol. 133, no. 12, pp. 1247-1257, 2007., http://dx.doi.org/10.1061/(ASCE)07339399(2007)133:12(1247).

[16] G. P. Cimellaro and D. Lopez-Garcia, "Algorithm for design of controlled motion of adjacent structures," J. Struct. Control Health Monit., vol. 18, no. 2, pp. 140-148, 2009, http://dx.doi.org/10.1002/stc.357.

[17] H. Roh, G. P. Cimellaro, and D. Lopez-Garcia, "Seismic response of adjacent steel structures connected by passive device," $A d v$. Struct. Eng., vol. 14, no. 13, pp. 499-517, 2011, http://dx.doi.org/10.1260/1369-4332.14.3.499.

[18] S. Naserkhaki, A. Aziz, and N. A. Farah, "Pourmohammad, H. Parametric study on earthquake induced pounding between adjacent buildings," J. Eng. Mech., vol. 43, no. 4, pp. 503-526, 2012, http://dx.doi.org/10.12989/SEM.2012.43.4.503.

[19] F. Palacios-Quiñonero, J. M. Rossell, J. Rubió-Massegú, and H. R. Karimi, "“Structural vibration control for a class of connected multistructure mechanical systems", J," Math. Probl. Eng., vol. 12, no. 1, pp. 1-23, 2012, http://dx.doi.org/10.1155/2012/942910.

[20] E. Tubaldi, M. Barbato, and S. Ghazizadeh, "A probabilistic performance-based risk assessment approach for seismic pounding with efficient application to linear systems," J. Struct. Saf., vol. 36-37, pp. 14-22, May 2012., http://dx.doi.org/10.1016/j.strusafe.2012.01.002.

[21] M. Barbato and E. Tubaldi, "A probabilistic performance-based approach for mitigating the seismic pounding risk between adjacent buildings," J. Earthq. Eng. Struct. Dyn., vol. 42, no. 8, pp. 1203-1219, Oct 2012., http://dx.doi.org/10.1002/eqe.2267.

[22] C. C. Patel and R. S. Jangid, "Seismic response of dynamically similar adjacent structures connected with viscous dampers," IES J. Part A Civ. Struct. Eng., vol. 3, no. 1, pp. 1-13, Feb 2010, http://dx.doi.org/10.1080/19373260903236833.

[23] H.-S. Kim and J.-W. Kang, "Seismic response control of adjacent buildings using shared tuned mass damper," J. Korean Assoc. Spat. Struct., vol. 14, no. 3, pp. 75-84, Sep 2014, http://dx.doi.org/10.9712/KASS.2014.14.3.075.

[24] S. Naserkhaki, M. El-Rich, F. N. A. A. Aziz, and H. Pourmohammad, "Pounding between adjacent buildings of varying height coupled through soil," J. Struct. Eng. Mech., vol. 52, no. 3, pp. 573-593, Nov 2014, http://dx.doi.org/10.12989/sem.2014.52.3.573.

[25] L. A. Pérez, S. Avila, and G. Doz, "Seismic response control of adjacent buildings connected by viscous and hybrid dampers", in Dynamics of Civil Structures, vol. 4, no. 1, F. N. Catbas, Ed., Cham: Springer, 2014, pp. 433-440.

[26] K. Bigdeli, W. Hare, J. Nutini, and S. Tesfamariam, "Optimizing damper connectors for adjacent buildings," J. Opt. Eng., vol. 17, no. 1, pp. 47-75, Nov 2015, http://dx.doi.org/10.1007/s11081-015-9299-5.

[27] E. Tubaldi, "Dynamic behavior of adjacent buildings connected by linear viscous/viscoelastic dampers," J. Struct. Control Health Monit., vol. 22, no. 8, pp. 1086-1102, Feb 2015, http://dx.doi.org/10.1002/stc.1734. 
[28] H. M. Faridani and A. Capsoni, "A modified replacement beam for analyzing building structures with damping systems," J. Struct. Eng. Mech., vol. 58, no. 5, pp. 905-929, Jun 2016, http://dx.doi.org/10.12989/sem.2016.58.5.905.

[29] M. Abdeddaim, A. Ounis, M. K. Shrimali, and T. K. Datta, "Retrofitting of a weaker building by coupling it to an adjacent stronger building using MR dampers," J. Struct. Eng. Mech., vol. 62, no. 2, pp. 197-208, Apr 2017, http://dx.doi.org/10.12989/sem.2017.62.2.197.

[30] Z. Guenidi, M. Abdeddaim, A. Ounis, M. K. Shrimali, and T. K. Datta, "Control of Adjacent Buildings Using Shared Tuned Mass Damper," Procedia Eng., vol. 199, pp. 1568-1573, 2017, http://dx.doi.org/10.1016/j.proeng.2017.09.059.

[31] L. A. Pérez Peña, "Resposta dinâmica de edificações adjacentes acopladas: considerações sobre a interção solo - estrutura," Ph.D. dissertation, Dep. Eng. Civ., Univ. Brasília, Brasília, 2017.

[32] S. Rahimi and M. Soltani, "Expected extreme value of pounding force between two adjacent buildings," J. Struct. Eng. Mech., vol. 61, no. 2, pp. 183-192, Jan 2017, http://dx.doi.org/10.12989/sem.2017.61.2.183.

[33] J. Song, K. T. Tse, G. Hu, S. Liang, and L. Zou, "Dynamic properties of wind-excited linked tall buildings considering both intrabuilding and interbuilding structural couplings," J. Struct. Eng., vol. 144, no. 1, pp. 6017007, Jan 2018, http://dx.doi.org/10.1061/(ASCE)ST.1943-541X.0001928.

[34] P. Pippi, P. Bernardes Jr., S. Avila, M. Morais, and G. Doz, "Dynamic response to different models of adjacent coupled buildings," J. Vib. Eng. Tech., vol. 8, no. 1, pp. 247-256, Apr 2019., http://dx.doi.org/10.1007/s42417-019-00102-7.

[35] M. Asano, Y. Yamano, K. Yoshie, Y. Koike, K. Nakagawa, and T. Murata, "Development of active-damping bridges and its application to triple high-rise buildings," JSME Int. J. Ser. C, vol. 46, no. 3, pp. 854-860, 2003., http://dx.doi.org/10.1299/jsmec.46.854.

[36] K. Yoshie, Y. Koike, H. Shiraki, M. Asano, and Y. Yamano, “Active-damping bridges for buildings of Harumi Island Triton Square (Part 5, Control effect evaluation using performance records)," in Summaries of Tech. Papers Annu. Meeting Architectural Inst. Japan, B-2 Struct. Struct. Dyn. Nuclear Power Plants, 2003, pp. 717-718.

[37] F. Pratesi, S. Sorace, and G. Terenzi, "Analysis and mitigation of seismic pounding of a slender R/C bell tower," J. Eng. Struct., vol. 71, pp. 23-34, Jul 2014, http://dx.doi.org/10.1016/j.engstruct.2014.04.006.

[38] ARTeMIS Modal Analysis - Structural Vibration Analysis (v4.0.6 - 2015), Aalborg, Denmark, 2015.

[39] R. J. Allemang, "Investigation of some multiple input/output frequency response function experimental modal analysis techniques," Ph.D. dissertation, Dept. Mech. Eng., University of Cincinnati, 1980.

[40] R. J. Allemang and D. L. Brown, “A correlation coefficient for modal vector analysis,” in Proc. Int. Modal Analysis Conf., 1982, pp. $110-116$.

[41] J. Kennedy and R. Eberhart, "Particle swarm optimization," in Proc. of IEEE Int. Conf. on Neural Networks, 1995, pp. 1942-1948.

[42] MATLAB - Matrix Laboratory (R2009b). MathWorks - MATLAB and Simulink for Technical Computing, Massachusetts, U.S.A., 2009.

[43] S. Braun, D. Ewins, and S. S. Rao, Encyclopedia of Vibration. San Diego: Academic Press, 2002.

[44] R. W. Clough and J. Penzien, Dynamics of Structures. New York, USA: McGraw Hill, 2003.

[45] AqDados 7.02, Acquisition Program Signals: User Manual, Ver. 7. Lynx Electronic Technology Ltd., São Paulo, 2003.

[46] J. Franceschini and H. M. Gomes, "Avaliação de amortecimento estrutural usando-se o método do 'Random Decrement'," Rev. Eng. Estudo Pesqui., vol. 10, no. 1, pp. 39-48, 2010.

[47] S. S. Rao, Mechanicals Vibrations. USA: Prentice Hall Pearson, 2010.

[48] Quimidrol. "Empresa de importação de produtos químicos e farmacêuticos.” http://www.quimidrol.com.br/quimica (accessed July 1, 2016).

Author contributions: Peña developed the theoretical formalism, performed the analytic calculations, and performed the numerical simulations and experimental tests. Doz and Avila supervised the project and contributed to the design and implementation of the research, to the analysis of the results and to the writing of the manuscript. Luis Alejandro Perez Peña \& Graciela Nora Doz - conceptualization, supervision, writing, data curation, formal analysis. Suzana Moreira Avila - conceptualization, supervision, writing;, data curation, formal analysis.

Editors: Bernardo Horowitz, José Luiz Antunes de Oliveira e Sousa, Guilherme Aris Parsekian. 